\title{
THE EFFECT OF HUMAN GROWTH HORMONE IN HYPOPITUITARY DWARFISM*
}

\author{
BY
}

\author{
A. PRADER, RUTH ILLIG, JUDITH SZÉKY, and H. WAGNER \\ From the Paediatric Department of the University of Zürich, Switzerland
}

(RECEIVED FOR PUBLICATION MAY 14, 1964)

Pituitary growth hormone is a polypeptide molecule with a wide range of effects on protein, lipid, and carbohydrate metabolism (Korner, 1961; Raben, 1962; Finkel, 1962; Sirek and Sirek, 1964; Knobil and Hotchkiss, 1964). It promotes growth through its protein anabolic (nitrogen-retaining) effect. Growth hormones from different species show differences in physical, chemical, and immunological properties and a marked degree of species specificity in their physiological activity. In man only human growth hormones are effective. The molecular weight of human gowth hormone (HGH) is 29,000 . Its structure is not yet exactly known. As yet it can only be obtained by extracting human pituitaries gained at necropsy. The amount available is, therefore, still seriously limited.

In 1958 Raben published the first report of the successful treatment of a hypopituitary dwarf with HGH. Since then considerable experience has accumulated (Hutchings, Escamilla, Deamer, and $\mathrm{Li}$, 1959; Beck, McGarry, Dyrenfurth, Morgen, Bird, and Venning, 1960; Shepard, Waxman, Bernstein, and Ferrier, 1960; Lipsett, Bergenstal and Dhyse, 1961 ; Prader and Illig, 1962; Raben, 1962; Vest and Girard, 1962; Aarskog, 1963; Daughaday and Parker, 1963; François, Frederich, Bertrand, Gilly and Morelon-Bachelot, 1963; Trafford, Lillicrap and Lessof, 1963; Tanner, 1963b), and there is no doubt that HGH does correct many aspects of the complex metabolic disturbance in hypopituitary dwarfism and that it does promote growth in most hypopituitary dwarfs. However, we still know little about the optimal preparation and the optimal dosage of HGH, about the ultimate results, about the effect on bone maturation, about possible complications, or about the effect of HGH on other types of dwarfism. Progress in this field is handicapped by the limited

- Windermere lecture, given by Prof. A. Prader at the meeting of the British Paediatric Association in Scarborough, April 1964. amount of HGH available, by our limited knowledge of the metabolic effect of HGH and its own turnover and metabolic fate, and by the difficulty of measuring $\mathrm{HGH}$ in biological fluids.

We have used HGH during the past four years and report here (1) some results of a standardized metabolic HGH test in dwarfs and its diagnostic and prognostic importance, (2) the growth effect of prolonged HGH therapy in a dosage that we believe to be in or near the physiological range, and (3) the clinical, metabolic, and immunological findings in patients who have developed antibodies against HGH.

Before presenting our findings it seems appropriate to make a few remarks about the diagnosis of growth hormone deficiency.

\section{Diagnosis of Growth Hormone Deficiency and of Hypopituitary Dwarfism}

We consider as hypopituitary those dwarfs whose growth and bone maturation are markedly retarded, who respond insufficiently to insulin-induced hypoglycaemia, and who show evidence of secondary insufficiency of the thyroid and/or the adrenal cortex.

It is still difficult to establish direct proof of growth hormone deficiency. Easy and reliable methods for measuring growth hormone in plasma and in urine are not yet available. The immuno-assay based on haemagglutination inhibition, originally proposed by Read and Bryan (1960), has disappointed most workers. We put an enormous effort into it and were finally forced to give up (Széky, Holländer, and Prader, 1961). The newer radio-immuno-assay, introduced by Hunter and Greenwood (1962) and by others (Utiger, Parker, and Daughaday, 1962; Glick, Roth, Yalow, and Berson, 1963; Utiger, 1964; Touber, Maingay, and de Ruyter, 1964), holds great promise. However, it seems that even the normal fasting subject may have growth hormone levels of 
nearly zero. Since hypoglycaemia is followed by a marked increase of the plasma growth hormone level (Roth, Glick, Yalow, and Berson, 1963; Hunter and Greenwood, 1964), it seems likely that the increase of the plasma growth hormone level, induced by insulin and measured by the new radio-immuno-assay, will become the ideal test to estimate maximal growth hormone secretion. We still know very little about the urinary excretion of growth hormone (Salinas, Mönckeberg, and Beas, 1963; Geller and Loh, 1963), but it may become possible to use this approach for recognizing growth hormone deficiency.

At the moment we still attach much importance to the intravenous insulin tolerance test. An insufficient response to insulin-induced hypoglycaemia, that is a delayed return of the blood glucose level to the normal, is a strong point in favour of $\mathrm{HGH}$ deficiency. The alternative explanation, an adrenocortical deficiency, is probably wrong. Fajans (1961) has clearly shown that patients with adrenocortical insufficiency have a normal hypoglycaemia responsiveness, provided they are well nourished and on desoxycorticosterone acetate. Hypopituitary dwarfs are usually well nourished and do not need desoxycorticosterone acetate. Additional evidence that their hypoglycaemic unresponsiveness is caused by HGH deficiency is the fact that it can usually be corrected with HGH in a dosage that we believe to be physiological.

The growth curve of most hypopituitary dwarfs is quite characteristic. It is usually normal in the first year and then gets flatter and flatter, moving more and more away from the average growth curve, and very gradually levels out completely at the age of about 30. There is no puberty and no pubertal growth spurt. The final height is $130-140 \mathrm{~cm}$. and the final skeletal age level rarely more than 13 or 14 years.

Our limited experience shows that these dwarfs, if treated with testosterone or other anabolic steroids, attain full skeletal maturity and a final height of around $150 \mathrm{~cm}$. This is more than in an untreated patient but is still not normal. These steroids have a protein anabolic effect similar to $\mathrm{HGH}$, but are apparently not able to replace completely the growth effect of HGH. This failure can probably be explained by the fact that anabolic steroids accelerate skeletal maturation more than growth.

At this point we should like to mention a possible relation between growth hormone and growth response to anabolic steroids. In animal experiments (Simpson, Asling, and Evans, 1950; Desaulles and Krähenbühl, 1962) as well as in clinical experience (Prader and Illig, 1962; van der Werff ten Bosch,
1962) subjects with severe growth hormone deficiency frequently show a marked resistance to anabolic steroids. In our clinical experience this resistance mainly concerns growth, but occasionally also bone maturation and virilization. It seems that some growth hormone is necessary to permit a full growth response to anabolic steroids.

\section{Type and Dosage of Human Growth Hormone}

All our studies have been performed with HGH extracted according to Raben's method and containing approximately 1.5 U.S.P. units per $\mathrm{mg}$. The dry powder was dissolved in $0.1 \mathrm{~N} \mathrm{HCl}$ and water. The final $p H$ of the solution was about 3 . The dosage used was with few exceptions always the same, namely $2 \mathrm{mg} . / \mathrm{m}^{2}$ of body surface area daily in the five-day metabolic HGH test and $5 \mathrm{mg} . / \mathrm{m}^{2}$ twice weekly for the long range treatment. For reasons which we shall discuss in a moment we feel that this dosage is in or perhaps just below the range of physiological replacement therapy. This point has some importance because we would expect physiological replacement therapy to be effective in the growth hormone-deficient, but not in the normal, subject. In a normal subject we would expect at most an immediate and transitory metabolic effect but no continued metabolic and growth response. Further we would not expect from physiological replacement therapy the appearance of signs of acromegaly such as hyperglycaemia or decreased glucose tolerance which are attributed to overproduction of $\mathrm{HGH}$.

The available information on the normal HGH plasma level and the HGH turnover rate, which makes us believe that our dosage is in or somewhat below the physiological range, is as follows. As Parker, Utiger, and Daughaday (1962), Roth et al. (1963), Hunter and Greenwood (1964), and Utiger (1964) have shown, the fasting HGH plasma level in the normal individual, measured by radio-immuno-assay, is about $2-8 \mathrm{~m} \mathrm{\mu g}$. $/ \mathrm{ml}$., and the half-life of intravenously injected HGH about 20-30 minutes. Parker et al. (1962) estimated the normal daily secretion rate in an adult to be around $5 \mathrm{mg}$. or $3 \mathrm{mg} . / \mathrm{m}^{2}$. Since this secretion rate is calculated on the assumption of a rather high plasma level of $10 \mathrm{~m} \mathrm{\mu g}$./ml., it may be rather lower in reality and may be similar to our dosage of $2 \mathrm{mg} . / \mathrm{m}^{2}$. One injection every one to three days of a hormone with a half-life of 20 minutes is of course far from being physiological. However, the intramuscular injections provide a slow absorption as shown by the HGH plasma level which is increased for many hours. Ideally, injections should probably be given at intervals not longer than 12 to 24 hours. However, since the growth- 
promoting effect is also present when only two injections a week are given, we have used a schedule of two injections a week, keeping the total dosage near $2 \mathrm{mg} . / \mathrm{m}^{2}$ day. Though a definite conclusion is not possible, the information just reviewed is strongly suggestive that our dosage is in or below and certainly not above the physiological range.

\section{A Standardized Metabolic HGH test}

We have developed a simple and standardized metabolic HGH test which allows us to evaluate the patient's response to $\mathrm{HGH}$.

The patient is put on an individual but rigidly constant diet containing $1 \cdot 3-2 \cdot 6 \mathrm{~g}$. protein per $\mathrm{kg}$. Any previous endocrine therapy is continued or had been stopped two to three months before the test. Urine is collected for daily determination of $\mathbf{N}$ and other constituents. Faeces are not collected. After a control period of at least 5 days the patient is given HGH daily for 5 to 6 days. Before and at the end of the HGH period plasma urea and other plasma constituents are determined and an intravenous insulin tolerance test with 4 units $\mathrm{m}^{2}$ is performed.

We have performed this test in 12 hypopituitary dwarfs 4 children with normal stature and 7 children with non-hypopituitary dwarfism served as controls. The most interesting results are those of $\mathrm{N}$ excretion and of the insulin tolerance test.

The decrease in daily urinary $\mathbf{N}$ excretion during HGH therapy is virtually identical with the increase in $\mathrm{N}$ retention, since faecal $\mathrm{N}$ is hardly affected. As expected the increase of $\mathbf{N}$ retention, expressed in $\mathrm{mg}$. $\mathbf{k g}$. or as percentage of pre-treatment $\mathbf{N}$ excretion (Metcalf and Greene, 1963), is much higher in the group with hypopituitary dwarfism than in the control group (Fig. 1). There is in fact hardly any overlap between the two groups. The absolute values are remarkably high and would decrease if the HGH treatment were continued.

We have similarly studied the effect of HGH on the excretion of creatine, calcium, and $x$-amino $\mathbf{N}$. In contrast to the marked difference in $\mathrm{N}$ excretion in the two groups studied we did not find a significant difference in the creatine, calcium, and $x$-amino $\mathbf{N}$ excretion in the two groups. As is usually seen with HGH therapy, the urinary creatine values dropped if they were high and the calcium excretion increased in both groups. Among the effects of HGH studied, $\mathrm{N}$ retention is appar $\mathrm{ntly}$ the only one that is clearly dependent on endogenous HGH secretion.

We feel that this controlled study confirms what was suggested by recent studies of Lipsett et al. (1961) and of Daughaday and Parker (1963), namely that HGH causes a greater $\mathrm{N}$ retention in individuals deficient in growth hormone than in individuals with normal growth hormone production. We feel also that this test is a valuable aid in the diagnosis of growth hormone deficiency. Since growth is based on $\mathbf{N}$ retention the test should enable one to predict which patients will show a good growth response to prolonged treatment with $\mathrm{HGH}$ in physiological dosage. Such a prediction is important and helpful as long as there is so little HGH available.

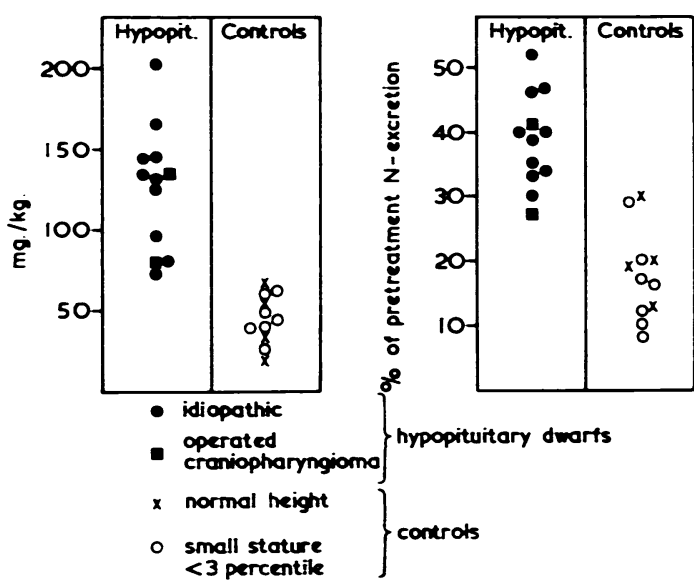

FIG. 1.-Increase in N retention with HGH Raben in a dosage of $2 \mathrm{mg} . \mathrm{m} \cdot{ }^{2} 24$ hours in hypopituitary dwarfs and in controls. The increase in $\mathbf{N}$ retention is calculated as difference of urinary $\mathbf{N}$ excretion between a 5-day period before therapy and from the 2 nd to the 6 th day of therapy under a constant diet. It is expressed in $\mathrm{mg}$. $\mathbf{k g}$. and in percentage of pretreatment $\mathbf{N}$ excretion.

The $\mathrm{N}$ retention caused by $\mathrm{HGH}$ is accompanied by a decrease in blood urea which also is more marked in the hypopituitary dwarfs than in the controls (Fig. 2). The blood $x$-amino $N$, which usually decreases under HGH treatment, showed an increase in most of the hypopituitary patients examined (Fig. 2).

Unresponsiveness to insulin-induced hypoglycaemia which is so typical of hypopituitary dwarfs is usually found to be fully corrected when the insulin tolerance test is repeated at the end of the HGH test (Fig. 3). The same is true for the occasionally seen fasting hypoglycaemia. In the control group the insulin tolerance test is normal and does not change in the course of the HGH test, indicating that normal carbohydrate metabolism is not much influenced by $\mathrm{HGH}$ in the dosage used.

\section{Growth Effect of Prolonged HGH Treatment}

Some of our patients were put on a prolonged HGH treatment following the HGH test in order to check our growth response prediction. 

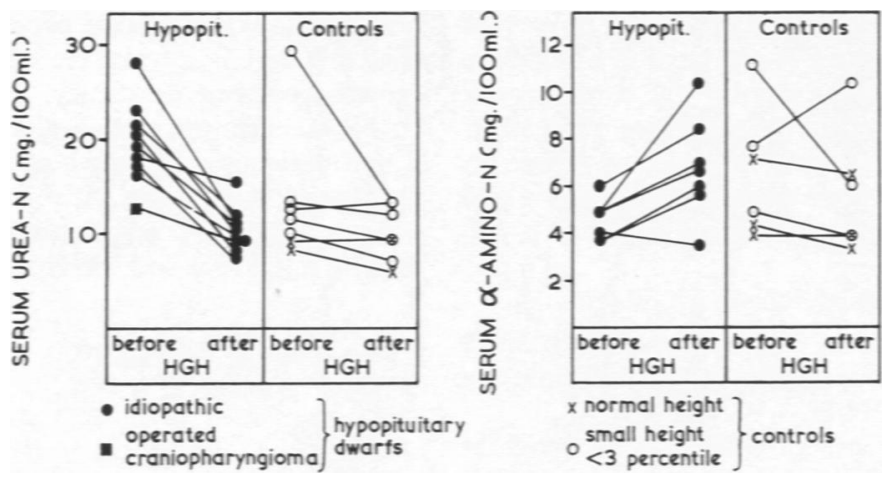

Fig. 2.-Effect of HGH Raben given for 5 days in a dosage of $2 \mathrm{mg} . \mathrm{m}^{2}$ per 24 hours on serum urea $\mathrm{N}$ and $x$-amino $\mathrm{N}$ in hypopituitary dwarfs and in controls.

Four non-hypopituitary dwarfs who had shown only a modest $\mathrm{N}$ retention in the metabolic HGH test did not accelerate growth during a four-month treatment period. This appears to confirm our prediction and the recent report of Daughaday and Parker (1963), though we realize that the measuring error and seasonal growth variation make it difficult to evaluate growth response in such a short period. However, we decided not to await further confirmation and to stop the experiment in order to save the hormone for our susceptible hypopituitary patients.

Nine hypopituitary dwarfs, who had all shown a high $\mathbf{N}$ retention in the $\mathrm{HGH}$ test, were treated for a period between nine months and three years. In most of them the previous treatment with thyroid and/or corticoids and/or anabolic steroids was continued. Contrary to expectations only 6 of them showed an unequivocal growth acceleration. Fig. 4 shows the growth velocity in centimetres a year before HGH treatment, during the first half year of treatment,

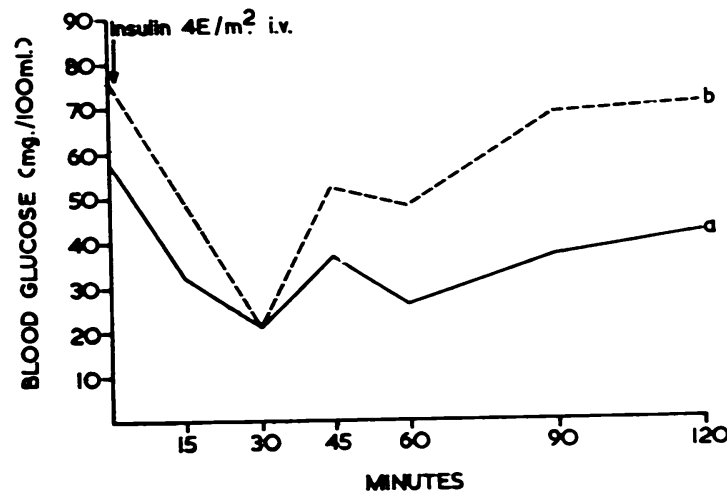

FIG. 3.- The effect of HGH on the insulin tolerance test in a boy with idiopathic hypopituitary dwarfism (H. Jürg, age 7 years 7 months), (a) before and (b) at the end of the metabolic HGH test. during the first whole year of treatment, and during the second and the third years of treatment. The thin lines represent the 6 successfully treated patients and the heavy lines the 3 resistant patients who developed HGH antibodies as we shall see in a moment.

The mean growth rate in the 6 successful patients was $3.4 \mathrm{~cm}$. a year before the HGH treatment, $9.4 \mathrm{~cm}$. a year during the first 6 months of treatment, $8.8 \mathrm{~cm}$. a year during the whole first year, and 5.5 $\mathrm{cm}$. during the second year of treatment. Apparently the growth rate at first is above average, it then slows down to average, and in some patients it is below average in the course of the second and the third year. It has been suggested that this decrease of growth response might be caused by the development of HGH antibodies. In our experience this is not so. We think that it represents the typical

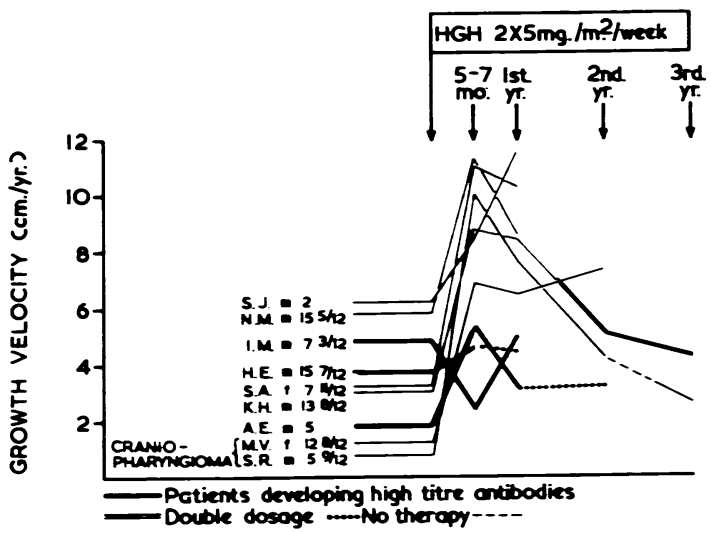

FIG. 4.- Growth velocity in hypopituitary dwarfs treated with HGH Raben in a dosage of $5 \mathrm{mg} . \mathrm{m}^{2}$ twice weekly. Growth velocity (in $\mathrm{cm}$. per year) before HGH treatment (horizontal lines), during the first half year of treatment, during the whole first year, and during the second and the third years of treatment. 
catch-up growth that we see for instance in a hypothyroid child when he is put on thyroid therapy. There too growth rate is first faster than average in spite of physiological dosage and slows down in the course of the treatment. It is not possible to discuss catch-up growth now, but it should be pointed out that catch-up growth is a general phenomenon seen whenever the cause of retarded growth can be corrected (Prader, Tanner, and von Harnack, 1963; Tanner, 1963a).

Figs. 5-11 show the details of the HGH effect on growth and development of two of our successfully treated patients.

Fig. 5 is a conventional growth chart of a boy who had a craniopharyngioma removed at the age of $2 \frac{1}{2}$ years. As usual this operation saved the patient from neurological deterioration, but led to a deterioration of his pituitary function. During the post-operative 3 years he scarcely grew at all despite combined substitution therapy with thyroid and cortisone in physiological dosage and despite the addition of large doses of anabolic steroids. This growth failure is a typical example of the unresponsiveness of children with severe organic pituitary insufficiency to anabolic steroids. At the age of 6 years HGH therapy was added to the former combined endocrine substitution therapy. During the 3 years of HGH therapy growth was markedly accelerated compared with the pre-treatment period. This is best seen in the serial photographs of our patient (Fig. 6). In the 37 months before HGH therapy he grew $2.5 \mathrm{~cm}$. and in the 41 months of $\mathrm{HGH}$ treatment $16 \mathrm{~cm}$. Under treatment his facial appearance and his body proportions changed from those of an infant to those of a normal schoolboy.

Fig. 7 shows height increments or growth velocity in centimetres a year of the same patient. This way of plotting growth gives a far better insight into the dynamics of growth than the conventional growth chart. It shows very clearly how our patient grew less than $1 \mathrm{~cm}$. a year in the years between the operation for his craniopharyngioma and the beginning of $\mathrm{HGH}$ therapy, that growth hormone increased his growth rate to $9 \cdot 6 \mathrm{~cm}$. a year during the first few months of therapy, and that it dropped later under the continued HGH therapy to about $4.6 \mathrm{~cm}$. a year. When HGH therapy was interrupted, growth decreased again to the original rate of less than $1 \mathrm{~cm}$. a year and increased to $4 \mathrm{~cm}$. a year when $\mathrm{HGH}$ treatment was taken up for the second time.

Fig. 8, from the same patient, is a conventional development chart showing height-age (Heimendinger, 1958), weight-age (Heimendinger, 1958), and bone-age (Tanner, Whitehouse, and Healy, 1962).
We still use this type of chart to evaluate and to demonstrate simultaneously the effect of a growthpromoting treatment on growth, on weight gain, and on skeletal maturation. Tanner (1962) has criticized this type of chart and has good reasons to do so. However, the chart still has its value if one is aware that in the normal subject bone-age will by definition always reach the top of the chart while height- and weight-age will reach variable levels depending on genetic and environmental influences. In our patients the chart clearly demonstrates that skeletal maturation, which hardly moved before $\mathrm{HGH}$ was given, accelerated under $\mathrm{HGH}$ treatment and was faster than growth and weight gain in spite of the fact that the dosage of anabolic steroids was much smaller than before. We have seen a similar acceleration of bone-age in all 5 hypopituitary patients whom we have treated successfully for more than nine months with a combination of $\mathrm{HGH}$ and thyroid in small doses and in some patients also cortisone and anabolic steroids.

Fig. 9 is again a conventional growth chart from a girl with idiopathic hypopituitary dwarfism. In this patient thyroid function is probably normal. At the age of 5 to 6 her growth was much accelerated by large amounts of anabolic steroids and small doses of thyroid. With thyroid alone in a physiological dosage growth slowed down. At the age of 8 years $\mathrm{HGH}$ as the only therapy was started and very successfully continued for the next 2 years.

The growth rate is again better analysed in a growth velocity chart (Fig. 10). Before therapy the growth rate is far below average, about $2 \mathrm{~cm}$. a year. With anabolic steroids it is about $8 \mathrm{~cm}$. a year or just above average. With thyroid alone it is again below average but still better than without any treatment. Growth hormone accelerated the growth rate to $10 \mathrm{~cm}$. during the first year and to about $8 \mathrm{~cm}$. during the second year. This chart is a beautiful demonstration of the growth-promoting effect of the two anabolic hormones, the anabolic steroids on one hand and HGH on the other hand.

The development chart of this patient (Fig. 11) is most interesting. It shows the well-known fact that anabolic steroids accelerate bone maturation more than growth, whereas $\mathrm{HGH}$ alone appears to accelerate growth more than bone maturation.

\section{Acquired HGH resistance and HGH antibodies}

After these examples of successfully treated patients we have to analyse our 3 growth-resistant hypopituitary dwarfs (Prader, Széky, Wagner, Illig, Touber, and Maingay, 1964). These 3 patients all developed high titres of specific $\mathrm{HGH}$ antibodies during the first few months of treatment. The 


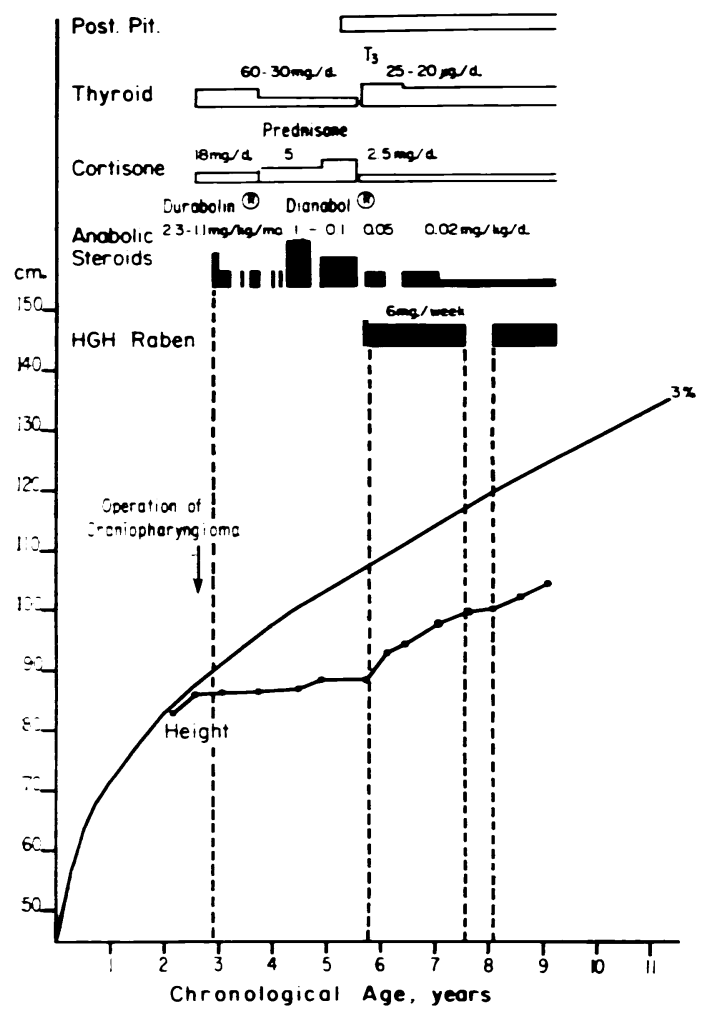

Fig. 5

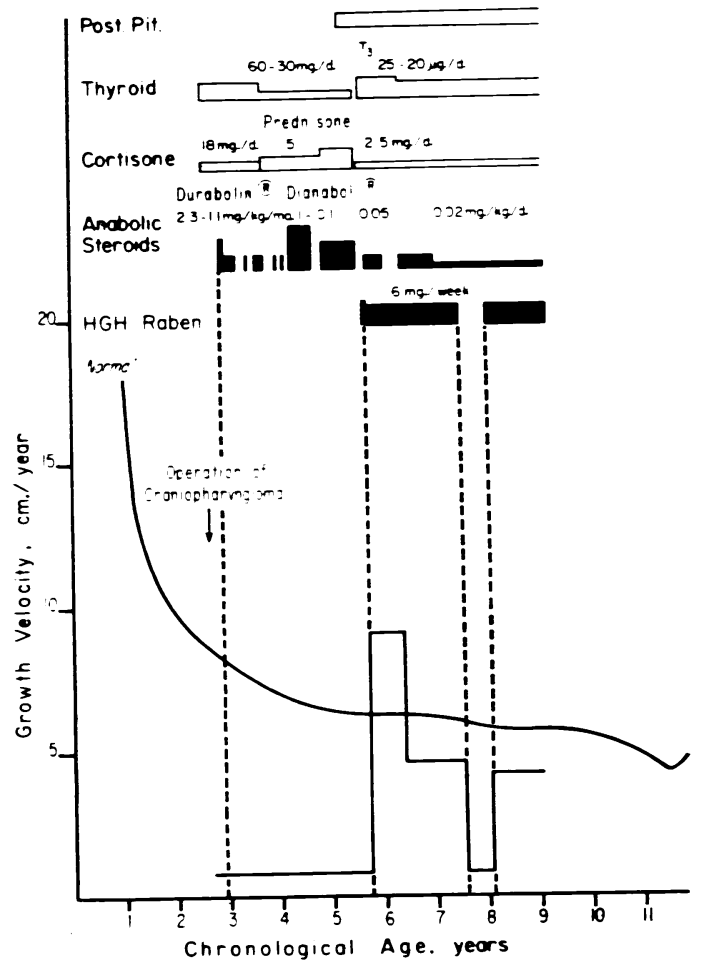

Fig. 7

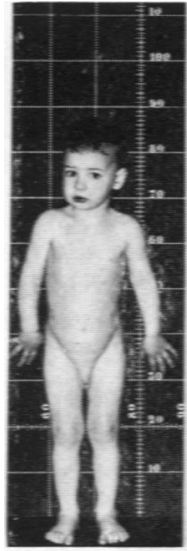

$2^{7 / 12}$

$86.0 \mathrm{~cm}$

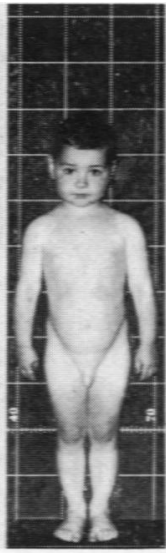

$5^{8 / 12}$

$88.5 \mathrm{~cm}$.

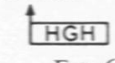

$7^{3 / 12}$

$99.0 \mathrm{~cm}$.

Fig. 6

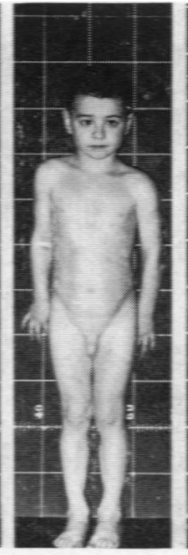

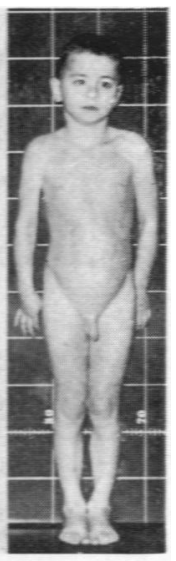

$91 / 12$

$104.5 \mathrm{~cm}$
FIG. 5.-Growth of a 'hypophysectomized' (removal of a craniopharyngioma at the age of $2 \xi$ ) boy (St. René) before and during treatment with HGH.

FIG. 6.-Serial photographs of a 'hypophysectomized' boy (same patient as in Fig. 5) before and during treatment with HGH.

FIG. 7.-Growth velocity of a 'hypophysectomized' boy (same patient as in Fig. 5 and 6) before and during treatment with HGH.

FIG. 8. - Development of a 'hypophysectomized' boy (same patient as in Fig. 5-7) before and during treatment with HGH.

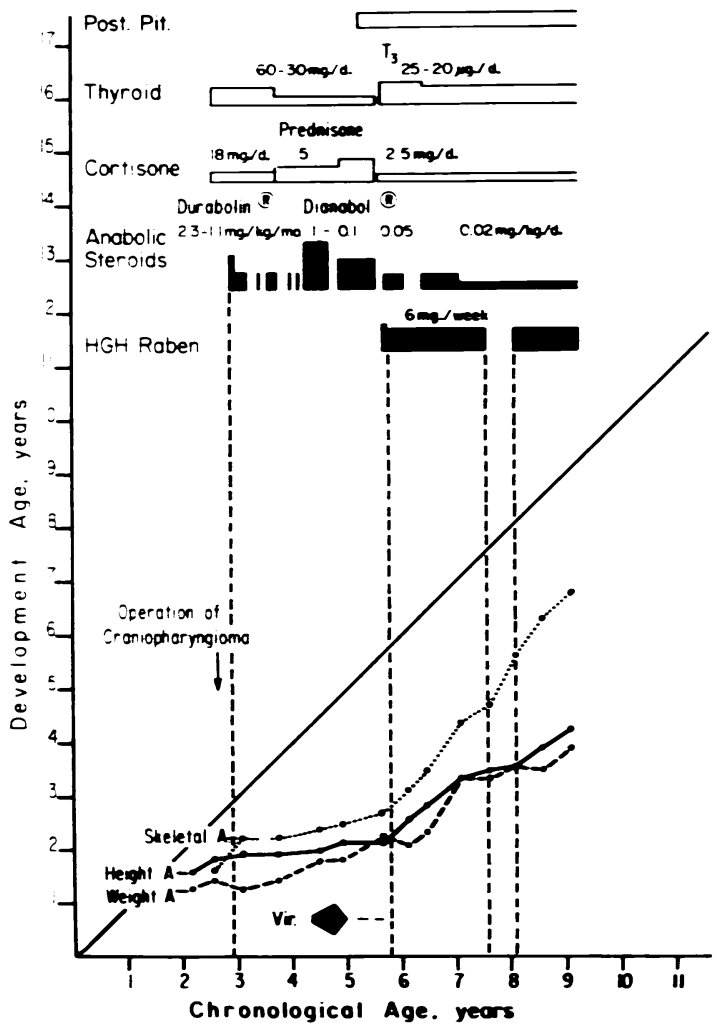

Fig. 8 

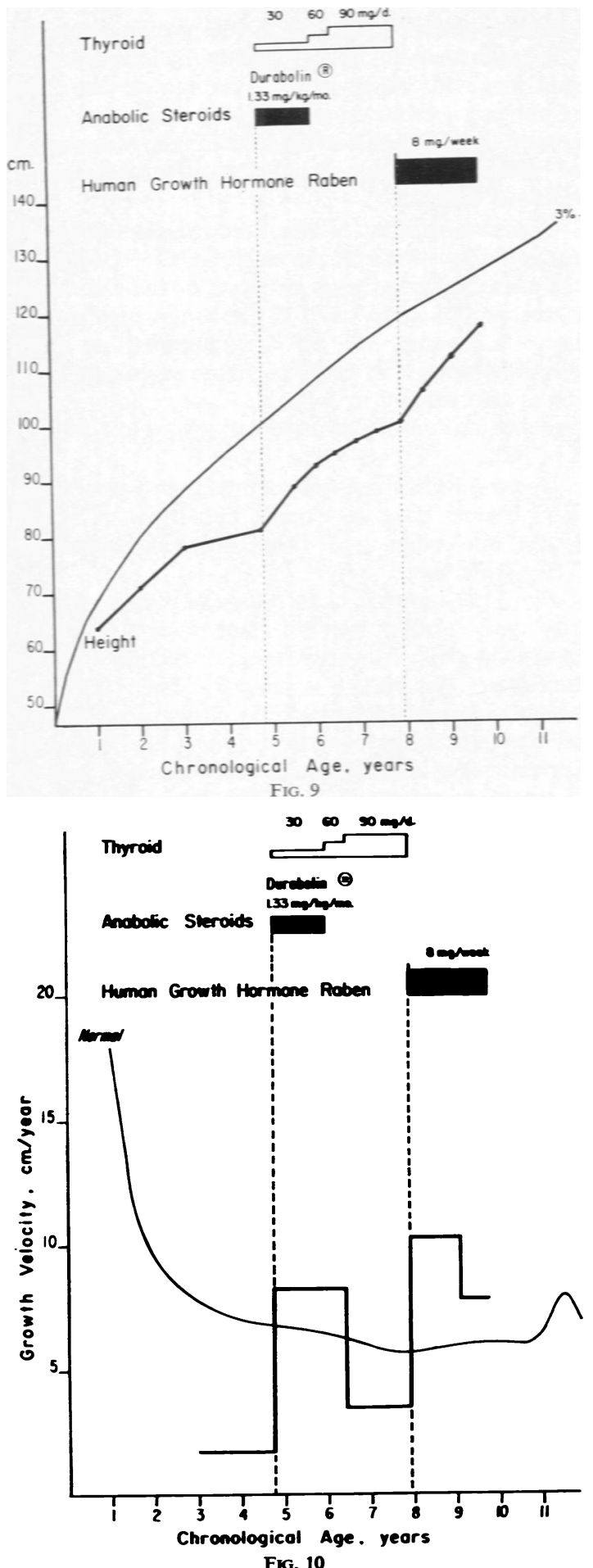

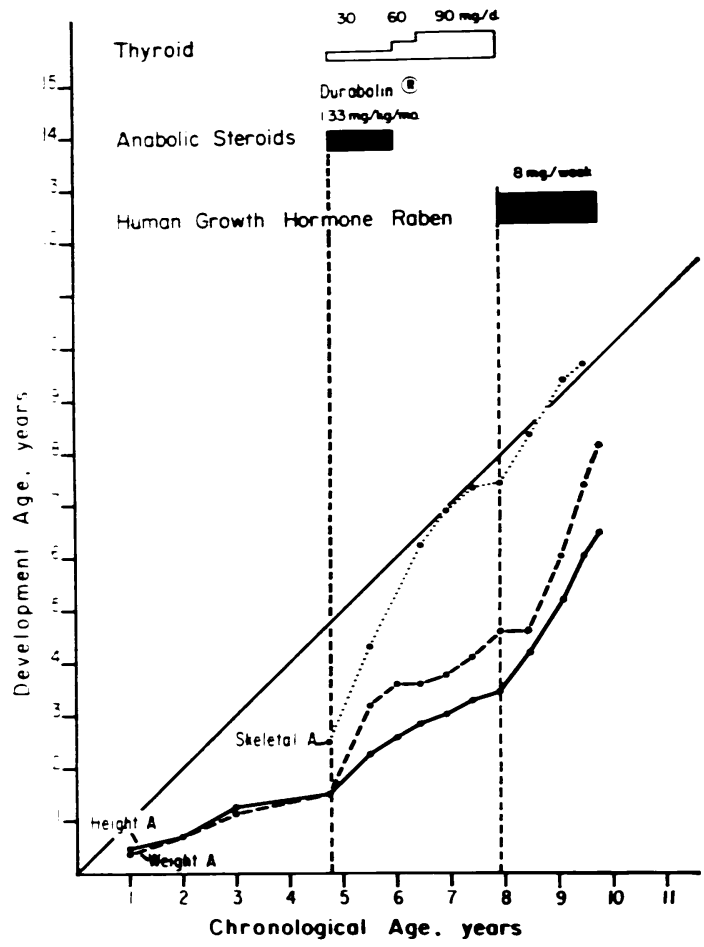

FKG. 11

FIG. 9.-Growth of a girl with idiopathic hypopituitary dwarfism (S. Anna).

FIG. 10.-Growth velocity of a girl with idiopathic hypopituitary dwarfism (same patient as in Fig. 9) before and during treatment with HGH.

FIG. 11.-Development of a girl with idiopathic hypopituitary dwarfism (same patient as in Figs. 9 and 10) before and during treatment with HGH.

metabolic and growth effect of HGH was suppressed. The other 6 patients, some of them treated for a much longer period, developed no or only low titres of HGH antibodies which did not interfere with the HGH effect on growth and metabolism.

Our group in Zürich and Dr. Touber and Dr. Maingay in Amsterdam* demonstrated the development of these antibodies and their specificity by two different methods. One is the haemagglutination method (Széky, Hässig, and Prader, 1962) and the other the radio-immuno-assay method (Touber et al., 1964). The basis and the results of these methods are as follows.

The sera of our 3 patients agglutinate HGHcoated sheep erythrocytes but do not agglutinate erythrocytes coated with human albumin, with

- Central Laboratory of the Netherlands Red Cross Blood Transfusion Service (Director: Prof. J. J. van Loghem). 


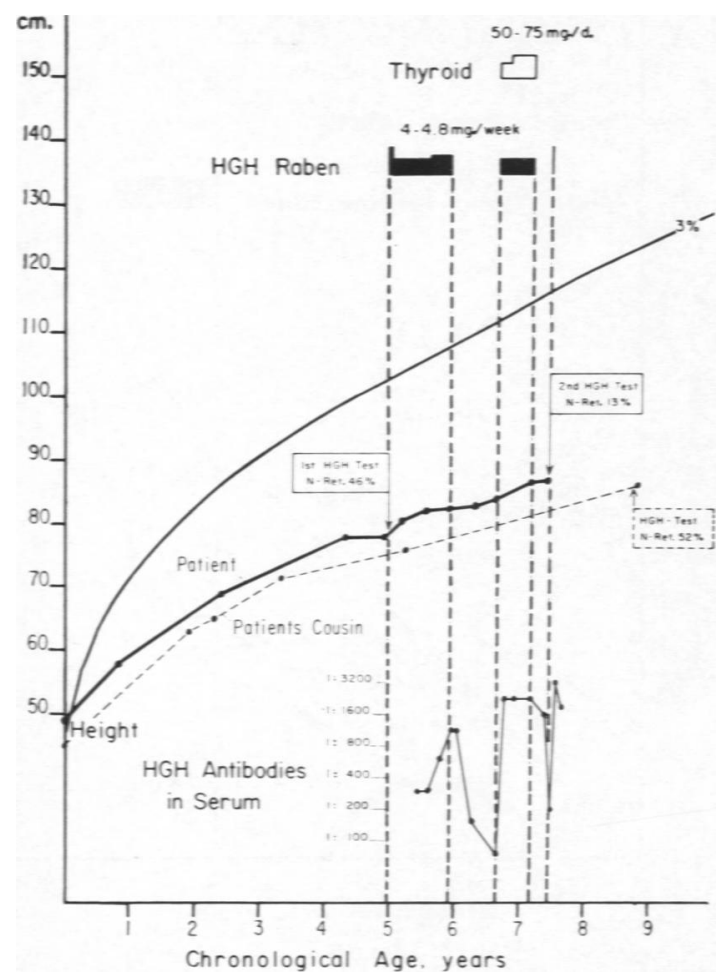

FIG. 12.-Growth of a boy with familial hypopituitary dwarfism (A. Ernst) before and during treatment with $\mathrm{HGH}$, and development of agglutinating HGH antibodies which blocked the HGH effect on $N$ retention and on growth. The interrupted growth line represents the patient's untreated girl cousin (S. Margrit) who has the same type of dwarfism. (From Prader et al. (1964).)

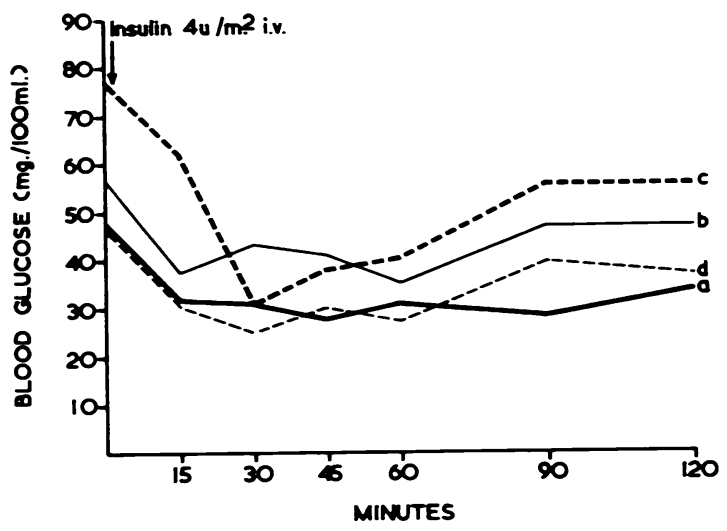

FIG. 13.- The effect of HGH on the insulin tolerance test in a boy with idiopathic hypopituitary dwarfism (I. Manuel, age 8) before and after the appearance of HGH antibodies. Lines $a$ and $b$ without $H G H$ and lines $c$ and $d$ with HGH. Lines $a$ and $c$ before and lines $b$ and $d$ after the development of antibodies. (From Prader et al. (1964).) human $\gamma$-globulin, or with bovine growth hormone. The agglutination can be inhibited by incubating the sera first with HGH or with human serum. Sera of patients with acromegaly are more effective in this respect than sera of normal individuals, whereas sera of patients with hypopituitary dwarfism have only a minimal effect.

Autoradiography of the immuno-electrophoretic pattern of serum incubated with $\mathrm{HGH}^{131}$ I shows, in the same patients, large amounts of the radioactive hormone bound to the $7 \mathrm{~S}-\gamma$-globulin precipitation line. This can still be demonstrated in serum dilutions up to 1 in 10,000 . Some $\gamma$-globulin binding is also present in 3 of the 6 successfully treated patients, but only in serum dilutions up to 1 in 10 or 1 in 100 .

The results of these two methods show clearly that our patients have developed high titres of specific HGH antibodies and that those antibodies are 7 S- $\gamma$-globulins.

Fig. 12 is a growth chart of one of these patients, a boy with familial hypopituitary dwarfism. HGH treatment given between the ages of 5 and 8 did not accelerate the patient's growth. The HGH test before treatment increased the $\mathrm{N}$ retention by $46^{\circ}$ \% of the preceding control urinary $N$. After the appearance of antibodies the same test increased the $\mathrm{N}$ retention only by $13 \%$. The agglutination antibody titre increased during HGH treatment and dropped when treatment was interrupted. HGH given several months after treatment had been stopped caused a precipitous drop and a quick rebound, typical of an anamnestic immune reaction.

Fig. 13 shows the results of the insulin tolerance test in another patient who developed HGH antibodies. Before the appearance of antibodies, the blood glucose curve is flat (a) and gets normal under HGH (c). After the development of antibodies the flat curve (b) can no longer be corrected with HGH (d).

In summary, the treatment of these patients with exogenous and probably somewhat denatured HGH stimulated the production of HGH antibodies which suppressed the effect of exogenous HGH on protein and carbohydrate metabolism. The fact that the antibodies can be absorbed by serum of patients with acromegaly but not by serum of hypopituitary dwarfs suggests that these antibodies are not only active against exogenous HGH but also against endogenous HGH.

The presence or the development of haemagglutinating HGH antibodies has previously been reported by Conti, Sereno, Luchetti, Recchia, and Isidori (1962) and by Trafford et al. (1963). However, these workers found only low titres of antibodies, 
which apparently did not suppress the HGH effect on metabolism and growth.

We do not yet know why 3 out of our 9 patients developed HGH antibodies with such a disastrous clinical result. It could be that these 3 patients have never produced any $\mathrm{HGH}$ at all and have, therefore, no immunological tolerance for $\mathrm{HGH}$, whereas the 6 other patients secrete small but insufficient amounts of HGH and have, therefore, a normal immunological tolerance for it.

The importance of our observation about HGH antibodies is twofold. As doctors we deplore this unexpected and disappointing complication of an enthusiastically welcomed new type of treatment. As scientists we note with interest that man is able to develop antibodies against a homologous protein hormone, which suppress the physiological effect of this hormone.

\section{Summary}

Human growth hormone (HGH) Raben has been used in a dosage of $2 \mathrm{mg}$. $/ \mathrm{m} .^{2} /$ day or $5 \mathrm{mg}$. $/ \mathrm{m}^{2}$ twice weekly. This dosage is probably in or below, but certainly not above, the range of physiological replacement therapy.

In a standardized five-day metabolic HGH test hypopituitary dwarfs retain more $\mathbf{N}$ than children without GH deficiency. This test is a valuable diagnostic help in hypopituitary dwarfism.

A prolonged treatment with $\mathrm{HGH}$ accelerates growth in hypopituitary dwarfs but not in children without GH deficiency. Growth rate, induced by this treatment, is first above average and later average or below average for age. This decreasing response to HGH is typical for the general phenomenon of catch-up growth and is not caused by the development of antibodies.

Of 9 hypopituitary dwarfs, treated for at least 9 months, 3 were growth resistant from the beginning in spite of a high $\mathrm{N}$ retention in the preceding $\mathrm{HGH}$ test. This resistance is caused by the development of high titres of specific HGH antibodies in the very first few months of treatment. These antibodies suppress the effect of HGH both on metabolism and on growth. The unexpected occasional induction in man of antibodies against a homologous protein hormone is of great interest. The possibility that these antibodies might be active not only against the exogenous but also against the endogenous hormone could have a far-reaching biological importance.

Prof. E. Uehlinger (Dept. of Pathology, University of Zürich), Prof. H. U. Zollinger (Dept. of Pathology, St. Gallen), and Prof. Chr. Hedinger (Dept. of Pathology, Winterthur) provided the human pituitaries. Dr. M. S.
Raben (New England Center Hospital, Boston) prepared the HGH. Dr. Trudi Mürset helped in the management of the patients, and Dr. Edna Sobel (Dept. of Pediatrics, Einstein College of Medicine, New York) in the preparation of the manuscript.

\section{REFERENCES}

Aarskog, D. (1963). Human growth hormone in dwarfism since birth. Amer. J. Dis. Child., 105, 368.

Beck, J. C., McGarry, E. E., Dyrenfurth, I., Morgen, R. O., Bird, E. D., and Venning. E. H. (1960). Primate growth hormone studies in man. Metabolism, 9, 699.

Conti, C., Sereno, L., Luchetti, L., Recchia, O., and Isidori, A. (1962). Detection of anti-STH antibodies in man. Folia endocr. (Roma), $15,163$.

Daughaday, W. H., and Parker, M. L. (1963). Sulfation factor measurement as an aid in the recognition of pituitary dwarfism. J. clin. Endocr., 23, 638.

Desaulles, P. A., and Krähenbühl, C. (1962). Differentiation of action of various anabolic steroids. In Protein Metabolism (Ciba int. Symposium, Leyden, 1962), ed. F. Gross, pp. 170-184. Springer, Berlin.

Fajans, S. S. (1961). Some metabolic actions of corticosteroids. Metabolism, 10, 951 .

Finkel, M. J. (1962). Human growth hormone. Metabolic effects and experimental and therapeutic applications. Amer. J. Med., 32, 588.

François, R., Frederich, A., Bertrand, J., Gilly, R., and MorelonBachelot (1963). Action de l'hormone de croissance humaine (HGH) sur le nanisme hypophysaire. Pédiatrie, 18, 49.

Geller, J., and Loh, A. (1963). Identification and measurement of growth hormone in extracts of human urine. J. clin. Endocr., 23, 1107.

Glick, S. M., Roth, J., Yalow, R. S., and Berson, S. A. (1963). Immunoassay of human growth hormone in plasma. Nature (Lond.), 199, 784.

Heimendinger, J. (1958). Die Ergebnisse von Körpermessungen an 5000 Basler Kindern von 0 bis 18 Jahren. Schweiz. med. Wschr., 88, 785 .

Hunter, W. M., and Greenwood, F. C. (1962). A radio-immunoelectrophoretic assay for human growth hormone. Biochem. J., 85, 39P.

- - (1964). Studies on the secretion of human-pituitary-growth hormone. Brit. med. J., 1, 804.

Hutchings, J. J., Escamilla, R. F., Deamer, W. C., and Li, C. H. (1959) Metabolic changes produced by human growth hormone (LI) in a pituitary dwarf. J. slin. Endocr., 19, 759.

Knobil, E., and Hotchkiss, J. (1964). Growth hormone. Ann. Rev. Physiol., 26, 47.

Korner, A. (1961). Growth hormone. In Modern Trends in Endocrinology, (Second Series), ed. H. Gardiner-Hill, pp. 19-42. Butterworths, London.

Lipsett, M. B., Bergenstal, D. M., and Dhyse, F. G. (1961). Metabolic studies with human growth hormone in dwarfism and acromegaly. J. clin. Endocr., 21, 119.

Metcalf, W., and Greene, H. G. (1963). A quantitative expression for nitrogen retention with anabolic steroids. I. Norethandrolone. Metabolism, 12, 899.

Parker. M. L., Utiger, R. D., and Daughaday, W. H. (1962). Studie on human growth hormone. II. The physiological disposition and metabolic fate of human growth hormone in man. J. clin. Invest., 41, 262.

Prader, A., and Illig, R. (1962). Use of anabolic agents in disorders of growth. In Protein Metabolism (Ciba Int. Symposium, Leyden, 1962), ed. F. Gross, pp. 383-397. Springer, Berlin.

- , Széky, J., Wagner, H., Illig, R., Touber, J. L., and Maingay, D. (1964). Lancet. In the press.

-, Tanner, J. M., and von Harnack, G. A. (1963). Catch-up growth following illness or starvation. J. Pediat., 62, 646.

Raben, M. S. (1958). Treatment of a pituitary dwarf with human growth hormone. J. clin. Endocr., 18, 901.

(1962). Growth hormone. I. Physiologic aspects. New Engl. J. Med., 265, 31.

Read, C. H., and Bryan, G. T. (1960). The immunological assay of human growth hormone. Rec. Progr. Hormone Res., 16, 187. 
Roth, J., Glick. S. M., Yalow, R. S., and Berson, S. A. (1963). Secretion of human growth hormone: physiologic and experimental modification. Metabolism, 12, 577.

Salinas, A., Möncketerg. F., and Beas, F. (1963). Immunological detection of growth hormone in normal human urine. Lancet, 2, 302.

Shepard, T. H., Waxman, S., Bernstein, N., and Ferrier, P. (1960). Human growth hormone. II. Further study of its effects on growth in dwarfism. J. Pediat., 57, 363.

Simpson, M. E., Asling. C. W., and Evans. H. M. (1950). Some endocrine influences on skeletal growth and differentiation. Yale J. Biol. Med., 23, 1.

Sirek, O. V., and Sirek, A. (1964). The physiology of growth hormone. Ergebn. inn. Med. Kinderheilk.. (n.s.). 21, 217.

Széky. J., Hāssig, A., and Prader, A. (1962). Ùber Antikōrper gegen menschliches Wachstumshormon vom Typus Raben bei Patienten mit Zwergwuchs. Helv. paediat. Acta, 17, 411.

_. Holländer, L., and Prader. A. (1961). Zur immunologischen Bestimmung des menschlichen Wachstumshormons: eine Vereinfachung der Readschen Technik. ibid., 16, 691.

Tanner. J. M. (1962). The evaluation of growth and maturity in children. In Protein Metabolism (Ciba int. Symposium, Leyden, 1962), ed. F. Gross, pp. 361-382. Springer, Berlin.

(1963a). The regulation of human growth. Child Develop., 34, 817
- (1963b). Methodische und therapeutische Studien des menschlichen Wachstumshormons in der Pādiatrie. 61. Tagung Deutsche Ges. f. Kinderhkeilk, Köln, September 1963.

—, Whitehouse, R. H., and Healy, M. J. R. (1962). A neu system for estimating skeletal maturity from the hand and wrist, with standards derived from a study of 2,600 healthy British children. International Children's Centre, Paris [ms.].

Touber. J. L., Maingay, D., and de Ruyter, H. A. (1964). A radioimmunoassay for human growth hormone in serum. Acta Med. Neerlandica. In the press.

Trafford, J. A. P., Lillicrap. D. A., and Lessof, M. H. (1963). Human growth hormone in pituitary infantilism. Lancet, 1, 1128.

Utiger. R. D. (1964). Extract on and radioimmunoassay of growth hormone in human serum. J. clin. Endosr., 24, 60.

- Parker, M. L., and Daughaday, W. H. (1962). Studies on human growth hormone. I. A radioimmunoassay for human growth hormone. J. clin. Invest., 41, 254.

van der Werff ten Bosch, J. J. (1962). Discussion. In Protein Metabolism (Ciba int. Symposium, Levden, 1962). ed. F. Gross, pp. 401-3. Springer, Berlin.

Vest, M.. and Girard, J. (1962). Stoffwechselwirkungen von gereinigtem menschlichem Wachstumshormon beim Zwergwuchs und bei der Anorexia nervosa im Kindesalter. Disch. med. Us s=hr., 87, 1705 